\title{
Migraciones indocumentadas. Proceso de acompañamiento en países de tránsito
}

\section{JORGE ANTONIO MORALES CARDIEL*}

En los albores del siglo XXI, México y Marruecos atraviesan por un nuevo paradigma migratorio, lo más sobresaliente de este hecho es el cambio con relación a sus patrones migratorios: de ser los tradicionales países de expulsión se convirtieron en lugares de tránsito de las migraciones indocumentadas.

Dicho incremento de migrantes en situación irregular y las subsecuentes violaciones a sus derechos humanos demuestra la incapacidad de los gobiernos en el manejo de las políticas públicas hacia la migración indocumentada. El proceso de acompañamiento ha sido desarrollado por organizaciones no gubernamentales (ONC) de corte confesional o laico a favor de los derechos humanos de los migrantes.

\section{Análisis de temas críticos}

\section{Antecedentes}

La nueva fase de la migración que une a México y Marruecos pretende alcanzar un mayor nivel de desarrollo económico, al circunscribirse en el modelo neoliberal que dictaminan las regiones más desarrolladas: en el caso de México, la región correspondiente a América del Norte (Estados Unidos a la cabeza); y respecto a Marruecos, la Unión Europea (España como puerta de entrada). Son ellos quie-

* Estudiante, Doctorado en Estudios del Desarrollo, Universidad Autónoma de Zacatecas nes dictaminan las directrices políticas hacia sus vecinos del sur, mediante el decreto de las medidas adoptadas para vigilar y persuadir a los contingentes de personas que intentan atravesar sus territorios. Lo anterior conlleva la asimilación de un control externalizado de fronteras en constante detrimento de los derechos humanos.

En estos sistemas migratorios contemporáneos que han evolucionado hasta tener $\mathrm{CO}^{-}$ mo punto de inflexión los países de tránsito se refleja el desarrollo de un proceso de reestructuración económica de la globalización neoliberal desde la periferia del mundo subdesarrollado hasta el norte desarrollado. Ahí la inmigración no se entiende como un proceso de reestructuración de la sociedad pese a estar sujetos a una rápida transformación socioeconómica, representada por el cambio del patrón migratorio. La política migratoria de los países de destino hacia los de tránsito se caracteriza por el control restrictivo de la inmigración indocumentada, lo que confirma el menoscabo de los derechos humanos de los migrantes de un tercer Estado. 
La situación de los derechos humanos hacia la inmigración irregular muestra retos importantes en términos de la lógica jurídica y política de las legislaciones internas, ante el déficit de la nota de universalidad, pues sólo se consagra como derecho universal el derecho a salir y regresar al propio Estado de origen, pero no queda plasmado el derecho a asentarse en el Estado que se elija libremente. Una consigna que más allá del célebre derecho humano universal a la libre movilidad arroja una reflexión fundamental en torno a si en efecto existe la intención de dotar de los derechos más elementales al migrante durante el tránsito hacia su destino, y si tales derechos humanos no erosionan la legitimad del Estado ante la incapacidad de controlar de modo adecuado esos flujos de migración.

Semejante yuxtaposición entre la soberanía del Estado y el derecho al libre tránsito es un hecho que precariza aún más la situación de los migrantes centroamericanos y subsaharianos en México y Marruecos. Saskia Sassen ${ }^{1}$ considera que tales principios, al asentarse en esta doble base (interna y externa), propician que el régimen de derechos humanos opere de manera parcial dentro de cualquier Estado nacional. No obstante, el Estado sigue representando un papel esencial en la elaboración y aplicación de las políticas de inmigración.

Las ONG, delegaciones religiosas u organizaciones laicas o un conjunto de ambas, muestran mayor comprensión hacia los migrantes indocumentados, incluso cada vez se involucran más, a medida que incrementa el número de violaciones a los derechos humanos de los migrantes. Según Saskia Sassen, la creciente capacidad de las ONG para plantear reivindicaciones hacia los derechos humanos se debe a que forman parte de la nueva configuración del orden internacional, cuyas implicaciones trascienden los límites del Estado.

${ }^{1}$ Saskia Sassen, ¿Perdiendo el control? La soberanía en la era de la globalización, España, Edicions Bellaterra, 2001.

\section{Fundamentación teórica}

Concerniente al concepto del acompañamiento, un tratamiento específico del término se encuentra en la Real Academia Española. Si bien dichas definiciones se caracterizan por su subjetividad y rigurosidad, representan un adecuado precedente para analizar el significado de una palabra que llega a convertirse en concepto de estudio. En ese sentido, indica que se refiere a la acción o efecto de acompañar o gente que va acompañando a alguien (nada nuevo en realidad); otra mención más profunda y adecuada es la que alude a un sostén o auxilio armónico.

Este soporte en el proceso de acompañamiento hacia los grupos de personas más vulnerables, como los migrantes indocumentados, es un servicio de asistencia humanitaria y empoderamiento legal de especial alcance que prioriza el acompañamiento en un nivel personal. Tal como lo sugiere la práctica de servicio humanitario, el acompañamiento es en sí mismo un conjunto de actitudes, principios y valores congruentes con la realidad del migrante, donde la hospitalidad y la solidaridad son los más destacados.

No obstante, las instituciones que prestan estos servicios de acompañamiento (ONG) se desprenden de la sociedad civil u organizaciones confesionales que forman parte de diversos grupos religiosos, incluso intentan ir más allá de la mera prestación de servicios asistenciales, ya que en la mayoría de los casos ofrecen una muy necesaria compañía. De acuerdo con Maurizio Pontin, la defensa de los derechos humanos para la Iglesia se centra en las doctrinas basadas en la fe que priorizan la caridad frente al desprotegido. ${ }^{2}$ En suma, tales actores enfocan su proceso de acompañamiento en las necesidades y preocupaciones del individuo, con el propósito de que recuperen la dignidad y la esperanza de frente al futuro. ${ }^{3}$

\footnotetext{
${ }^{2}$ Maurizio Pontin, «Iglesia y migraciones latinoamericanas», Colombia, CEPAM CIM, 1992.

${ }^{3}$ Joe Hampson, Thomas M. Crea, Rocío Calvo, Francisco Álvarez, «El valor del acompañamiento. La fe y las respuestas
} 


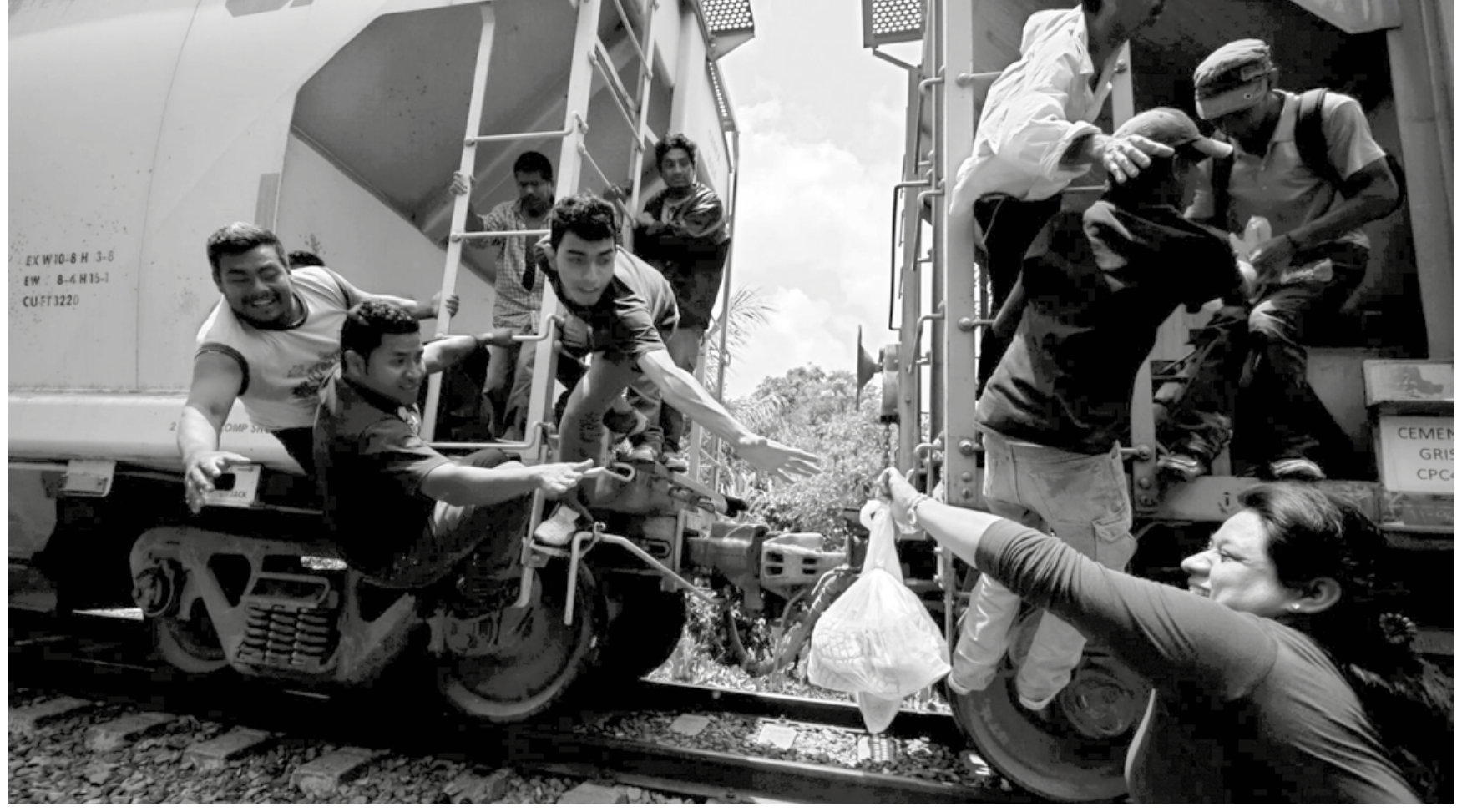

Un aspecto fundamental del acompañamiento hacia el migrante indocumentado es atenuar el enorme vacío de poder de las instituciones gubernamentales sobre el territorio. Para que el proceso de acompañamiento sea verdaderamente sustancial, los grupos encargados de implementarlo deben poseer fuertes lazos locales con las comunidades de acogida, es decir, pertenecer al territorio como actores locales clave, hecho que acentuará los necesarios valores de hospitalidad y solidaridad.

Por su parte, Montse Ventura ${ }^{4}$ sostiene que afrontar el acompañamiento supone primero, una vez asimilada la relación entre los actores involucrados, entender la interacción entre las partes; segundo, respetar la diversidad y unidad a fin de potenciar la facultad de hacerse cargo de problemas específicos. La Organización Internacional de las Migraciones (OIM) ${ }^{5}$ hace diversas recomendaciones asociadas a las

al desplazamiento», Migraciones forzadas, núm. 48, 2014, pp. 7-8.

${ }^{4}$ Montse Ventura, «Asesorar es acompañar», Profesorado, vol. 12, núm. 1, 2008, pp. 1-14.

${ }^{5}$ Organización Internacional de las Migraciones (OIM), Elementos para la incorporación del enfoque psicosocial en la atención, asistencia y reparación a las víctimas, Bogotá, OIM-Unidad para la Atención y Reparación Integral a las Víctimas, 2014. perspectivas de género o el curso vital de los grupos étnicos, con el objetivo de definir la forma de acompañamiento y evitar generalizaciones en la comprensión de casos.

Potenciar las formas del compromiso que representa el acompañamiento significa fortalecer la capacidad de ir hacia adelante, de tener el valor para defender lo que se considera crucial. Incluir todos esos aspectos en el proceso de acompañamiento implica también recuperar aspectos emocionales trascendentales de la vida. Trazar una línea desde las políticas públicas restrictivas y las prácticas xenofóbicas sociales a fin de que comience a emerger una multitud de sugerencias que posibilite hacer las cosas de manera reflexiva. En síntesis, tal como refiere Montse Ventura, acompañar es de igual modo asesorar, ${ }^{6}$ pero ello no se podría realizar sin ser solidario en el camino, sin empoderar al migrante para devolverle el control sobre su destino y la dignidad arrebatada durante el tránsito migratorio.

El concepto de empoderamiento es un principio que busca fortalecer las capacidades de las personas migrantes al devolverles la autoconfianza, la responsabilidad y la autonomía,

${ }^{6}$ Montse Ventura, op. cit.
Organizaciones no gubernamentales, religiosas, laicas o un conjunto de ellas, son las que tienen una mayor comprensión hacia los migrantes indocumentados en la medida que ellos padecen más violaciones a los derechos humanos. 
luego de que han sido víctimas de sistemáticas violaciones a sus derechos elementales; se pretende que puedan tomar nuevamente decisiones y que impulsen un cambio positivo con respecto a la situación en la que se encuentran. ${ }^{7}$ El empoderamiento para la OIM es una acción reparadora que se desprende del enfoque psicosocial de atención a las víctimas de daños y perjuicios a la dignidad humana.

Fernando Vidal y Julio Luis Martínez sostienen que el empoderamiento está ligado al papel que desempeña la religión en la identidad del individuo, consideran que el sujeto cuenta con cinco activos de empoderamiento: resiliencia, relaciones, bienes, derechos y representaciones. ${ }^{8}$ Destacan los fenómenos de reconocimiento de la sociedad de acogida y sus

Migraciones subsaharianas en Marruecos.
${ }^{7}$ OIM, op. cit.

${ }^{8}$ Fernando Vidal y Julio Luis Martínez, Religión e integración social de los inmigrantes: la prueba del ángel, España, CEIM/Universidad Pontificia de Comillas, 2006. dinámicas solidarias en las que el migrante se ha logrado integrar.

El incremento de migrantes en situación irregular por los países de tránsito, México y Marruecos, demuestra la incapacidad en el manejo de las políticas públicas hacia la inmigración indocumentada. Asimismo, pone en entredicho el reconocimiento de los gobiernos de ambos países el haber suscrito tratados internacionales que reconocen los derechos humanos del migrante. Adicionalmente, fragmentan la clásica línea dura gubernamental en términos de política fáctica ante el arribo de más migrantes en situación irregular; resalta, en particular, la falta de gobernanza existente sobre el territorio.

A partir del tratamiento de la ilegalidad del migrante por parte de los gobiernos mexicano y marroquí, el asunto se ha conducido únicamente desde el punto de vista de la migración como una condición impuesta dentro

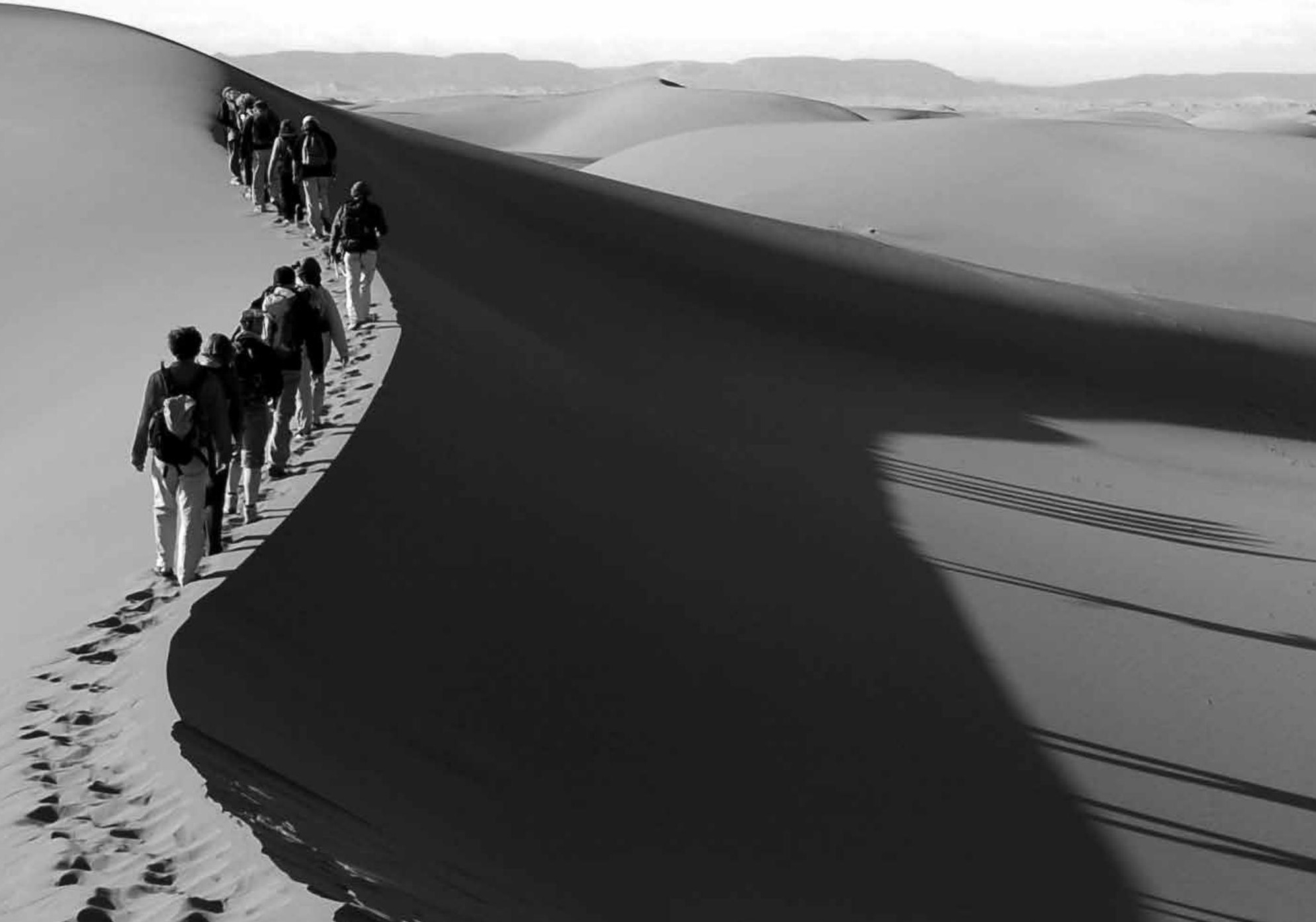


del marco normativo legal cuando no se puede cumplir con ciertas normas establecidas, por ejemplo, carecer de documentos que acrediten la estancia en el país. Esta realidad se ha recrudecido por quienes dictaminan las medidas para vigilar y persuadir a los contingentes de personas que intentan atravesar esos territorios.

En la última década, este proceso a favor de los derechos humanos ha sido desarrollado por las ONG, sean confesionales o laicas; además tiene su origen en un aspecto predecible: el fracaso de las políticas públicas hacia la migración de control fronterizo, que llevó a las autoridades gubernamentales a que se centraran en regulaciones del volumen y origen de los flujos de migrantes.

Derivado de lo anterior surgen los siguientes cuestionamientos: ¿qué significa el acompañamiento dentro de las migraciones indocumentadas de tránsito y qué relación posee con el empoderamiento del migrante? ¿En qué medida la articulación y coordinación entre las organiza- ciones a favor de los derechos de los migrantes indocumentados, localizadas en diferentes puntos del tránsito migratorio, generan un grado de solución a los problemas de violación de los derechos humanos y cómo pueden desembocar en la generación de una mayor gobernanza territorial? ¿Qué dificultades manifiesta el desarrollo de las acciones encaminadas hacia el acompañamiento para atender la migración indocumentada en tránsito, en qué nivel o fase de empoderamiento y gobernanza territorial se encuentra y cuáles han sido sus principales aportaciones en este sentido?

\section{Justificación}

La realidad sociopolítica de las autoridades al no cumplir con los principios de gobernanza territorial ha condenado a los migrantes a la ilegalidad. Complementariamente ha provocado que reaparezcan en escena actores locales que cuentan con distintos fundamentos y que se han

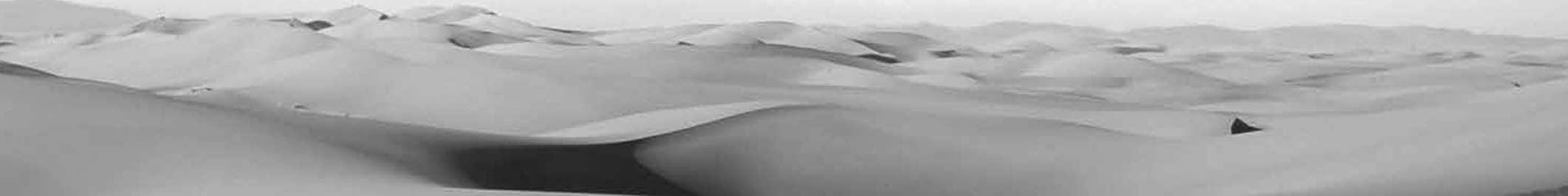


Ruta del tren entre Chiapas y Oaxaca, 25 de abril de 2014. Fotografía:

Organización Internacional para las Migraciones mostrado más activos en el tratamiento de las inmigraciones no autorizadas al asumir visiones pluralistas y flexibles respecto a la migración bajo el esquema de los derechos humanos. Su organización se vuelve indispensable en la medida en que el vacío de poder dejado por el Estado sigue creciendo.

Las organizaciones insertas en este escenario humanitario de acompañamiento se encuentran familiarizadas en diferentes grados con el entorno local por donde se realiza el desplazamiento de las inmigraciones no autorizadas. Por ende, deben conocer bien a las personas y las necesidades de las comunidades en las que estén instalados, con el objeto de propiciar mejores prácticas en función de la gobernanza territorial. Aunado a ello deben contar con una base empírica sobre el terreno. Tales son los casos de la Casa del Migrante de Saltillo, la Casa Emaús de Ciudad Acuña, la 72 de Tenosique o Camino a la Vida de Aguascalientes, el FM4 de Guadalajara, entre muchas otras a lo largo y ancho del país.

En una visión más amplia, el acompañamiento parece arrojar indicios cada vez más claros acerca de la prevalencia de una perspectiva comunitaria de ciertos grupos de la sociedad civil y de grupos voluntarios confesionales hacia el migrante indocumentado en tránsito, quienes se encuentran en vías de transformar su papel haciéndolo cada vez más activo, con relación a los migrantes en los procesos de toma de decisiones y de empoderamiento, en términos de la formulación de soluciones.

El proceso de acompañamiento y empoderamiento de los nuevos actores de la sociedad civil, confesional o laica, lleva implícito la veracidad y la honradez de la función preponderante de las instituciones públicas en la defensa de los derechos humanos de los migrantes sin documentos. De igual modo, evidencia una absoluta carencia de acciones políticas y sociales ante una situación de crisis humanitaria. Concerniente a los casos de México y Marruecos, no es posible dilucidar dicho fenómeno, no tanto por la ausencia de leyes o reglamentos suscritos a favor de los derechos humanos, sino por la falta de voluntad, la corrupción sistémica y el autoritarismo.

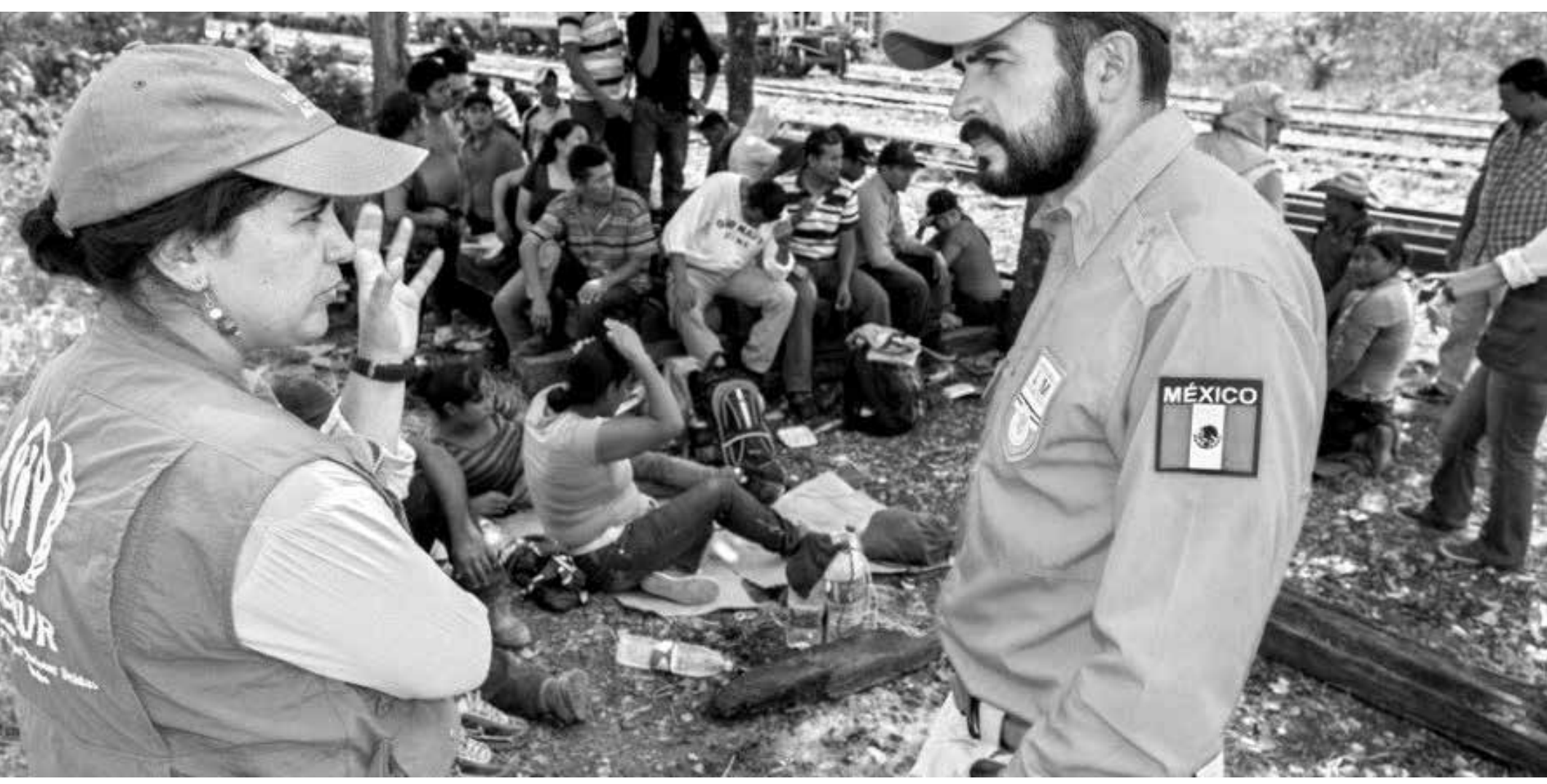

